\title{
The Transformation of Healthcare Buildings: The Challenges of the University of Pavia for Urban Regeneration
}

\author{
Alessandro Greco ${ }^{1, *}$, Daniela Besana ${ }^{1}\left(\mathbb{D}\right.$, Valentina Giacometti ${ }^{1}$, Mauro Mericco ${ }^{2}\left(\mathbb{D}\right.$, Silvia Lombardi ${ }^{2}$, \\ Andrea Borlini ${ }^{2}$, Roberto Turino ${ }^{3}$ and Cristiana Ruggeri ${ }^{3}$ \\ 1 Department of Civil Engineering and Architecture (DICAr), University of Pavia, 27100 Pavia, Italy; \\ daniela.besana@unipv.it (D.B.); valentina.giacometti@unipv.it (V.G.) \\ 2 Technical and Safety Area, University of Pavia, 27100 Pavia, Italy; mauro.mericco@unipv.it (M.M.); \\ silvia.lombardi@unipv.it (S.L.); andrea.borlini@unipv.it (A.B.) \\ 3 TEAM Pavia, 27100 Pavia, Italy; roberto.turino@teampavia.it (R.T.); cristiana.ruggeri@teampavia.it (C.R.) \\ * Correspondence: alessandro.greco@unipv.it
}

check for

updates

Citation: Greco, A.; Besana, D.

Giacometti, V.; Mericco, M.;

Lombardi, S.; Borlini, A.; Turino, R.;

Ruggeri, C. The Transformation of

Healthcare Buildings: The

Challenges of the University of Pavia

for Urban Regeneration.

Sustainability 2022, 14, 1517. https://

doi.org/10.3390/su14031517

Academic Editors: Annarita Ferrante

and Marc A. Rosen

Received: 6 December 2021

Accepted: 25 January 2022

Published: 28 January 2022

Publisher's Note: MDPI stays neutral with regard to jurisdictional claims in published maps and institutional affiliations.

Copyright: (c) 2022 by the authors. Licensee MDPI, Basel, Switzerland. This article is an open access article distributed under the terms and conditions of the Creative Commons Attribution (CC BY) license (https:// creativecommons.org/licenses/by/ $4.0 /)$.

\begin{abstract}
The theme of urban regeneration is currently one of the main actions of transformation policies. It presents an opportunity for cities' design, in particular historical centers, through joint actions aimed at creating synergies and connections between social, political, economic, and environmental aspects. It also becomes an opportunity to enhance the huge and complex Cultural Heritage, full of architectural values, memory, and history. At the same time, it appears increasingly inadequate and obsolete compared to the new needs of a changing society, of regulatory aspects, and of a general compatible approach to intervention to the more general policies of sustainable development, as required by the 2030 Agenda for Sustainable Development. A total of two case studies of the reuse and enhancement of hospital buildings of the University of Pavia are presented, which has a large building heritage spread throughout the city. In recent years, owing to the opportunities offered by funding, it has started transformation policies on some abandoned buildings through projects based on an interdisciplinary approach and a participatory design strategy. The article testifies to a potential method of intervention that can be exported to other contexts, after a previous test of the compatibility on the existing and on the urban context.
\end{abstract}

Keywords: built heritage; participated design process; reuse of public buildings; university; architecture for learning

\section{Introduction}

1.1. Urban Regeneration as Opportunity for Redevelopment and Sustainable Enhancement of the Cultural Heritage

Urban regeneration actions are one of the instruments useful to control the development of strategies aimed to overcome some critical aspects concerning the contemporary cities. This is, at least in national and European polices, one of the governance perspectives of the urban transformation processes [1].

These assertions arise from the observations that the city is changing, and it is necessary to control this complex situation, moving its development and transformation to shared and sustainable objectives, in a more general way. Therefore, it is important to adopt urban strategies able to create a relationship between the management methods of the decision-making processes of the public administration and the expectations of private investors and citizens [2]. For the implementation of the planning process that inevitably affects mobility, local economy and construction development, multidisciplinary skills, and the contribution of knowledge from all those involved are required. In this way, the Universities' role of investing in the construction of the new campus in the areas that have to be regenerated is very dynamic; for example, the new Bocconi Campus designed by SANAA in the area of the former Centrale del Latte in Milan or the area of King's Cross 
with the University of the Arts in London. It creates the city as the place where culture and knowledge are not only disseminated but also applied through interventions conscious of the historical, social, and cultural values of the areas.

Integrated strategies between universities, research centers, public authorities and citizens thus become solutions with which European cities can effectively face the economicenvironmental crisis, the climate threat, and current social challenges [3]. These synergies, in the regeneration of the consolidated historical city, must be able to connect the different political, social, environmental, and economic needs, and be able to involve the stakeholders in the implementation of actions that are both sustainable and capable of enhancing the urban heritage.

Some interventions, which include different levels of transformation of buildings and urban spaces, and define new design approaches that are recognizable for the overall architectural quality, can be traced back to real best practices capable of responding to the parameters of environmental, social, and economic demands [4].

The urban transformation project therefore represents an important collective opportunity for the city and its community, to increase both the potential for social cohesion and the ability to produce innovation, both strategic factors in which to invest $[5,6]$.

Furthermore, in the regeneration interventions on the compact city scale, it is necessary to deal with its specific characteristics; it has a clear growth limit and is regulated by an optimal relationship between density and system of public spaces [7]. In the dense city, therefore, its structure determines its livability, through a planning that is not structured for punctual interventions but rather organized in a systemic form, considering both the design of common spaces and high-quality sociality and the energy improvement interventions. Through these actions it is in fact possible to simultaneously improve the environmental and social quality of the city and to reduce land consumption, in a logic of consolidated city densification defined by places characterized by an adequate functional mix [8,9].

Starting from these premises, logic of "demolition and reconstruction" can therefore be understood to represent an impractical approach to the problem. The architectural heritage thus becomes a resource, a value on which to implement redevelopment policies at a technical, typological, and energy efficiency level, as well as regeneration in terms of social potential.

Urban regeneration processes can be declined in different strategies, attributable to the actions of Reduce, Reuse, and Recycle [10,11]. These design attitudes reinterpret the redevelopment interventions, and they are not limited to 'technical' buildings adjustments, but consider the resulting urban, social, and economic implications. In this way, the action is the overall enhancement of the Architectural Heritage, through different levels of intervention aimed for example at improving the identity and the architectural language of the buildings [12] and acting on the quality of public and private spaces, inserting new common areas and services for the neighborhood, optimizing the existing energy behavior with new architectural structure and interventions, and working on typological and functional transformation.

These proposals therefore apply intervention strategies that want to enhance the existing building, avoiding its demolition (excluding those aimed at the reconstruction of the original structure) but rather working on the addition or integration of new volumes where necessary for the new functional program; principles aimed at containing costs are adopted, using low-cost materials and industrialized systems and components; mainly dry construction solutions are used, lighter than traditional ones and compatible with existing structures; technological systems are used that ensure comfort and well-being but are also easy and cheap to maintain and manage, and flexible functional areas are provided, which are easily adaptable and transformable according to the needs of users over time $[13,14]$.

The aim is mainly to work according to quality criteria, understood as design and control of the performance capabilities of each intervention and seen as the compliance of the project with requirements, principles, criteria, and good practices. For example, the approaches based on the Performance Based Design (PBD) philosophy that act on the scale 
of the building and the efficiency of its construction elements (LCA, UNI/EN-ISO standards, protocols, and certifications such as LEED, BREEAM, and ITACA) and the Universal Design or Inclusive Design that adopt information and criteria to design spaces, products, and construction solutions that can be used by persons with different needs, referring in any case to punctual quantitative performance checks accredited internationally $[15,16]$.

The following case studies are to be considered as possible application examples of the principles of urban regeneration with respect to some SDG's Agenda 2030. The theme of urban regeneration can be read in close correlation with the theme of housing policies and with goals 7 Ensure access to affordable, reliable, sustainable and modern energy for all, in particular target 7.3 By 2030, double the global rate of improvement in energy efficiency and goal 11: Make cities and human settlements inclusive, safe, resilient and sustainable, target 11.1 By 2030, ensure access for all to adequate, safe and affordable housing and basic services and upgrade slums. The European Commission has raised the minimum energy efficiency target by 2030 to $30 \%$, declaring the need to put it first in EU energy policies. The new target to achieve energy efficiency at a national level is a decrease in consumption by 2030 by at least $40 \%$, equal to over 20 final Mtoe less than the current values. In the civil sector alone, including services and residential areas, which alone is responsible for over $35 \%$ of national $\mathrm{CO}_{2}$ emissions from energy processes, consumption will have to be reduced by $8-10$ Mtoe by 2030 , with a cut equal to approximately $20-25 \%$ of consumption.

The European target of increasing energy efficiency by $20 \%$ provides the achievement of 1483 Mtoe of total primary energy consumption in the EU in 2020 and 158 Mtoe in Italy, equal to $13.4 \%$. In 2015 the EU was at 1529.6 Mtoe of total consumption and Italy at 149.6 Mtoe, therefore already beyond the target owing to the tax incentives for building recovery and energy requalification, despite the Italian residential buildings being, from the energy point of view, among the least efficient in Europe. There are 12.2 million buildings and 31 million homes. Over $60 \%$ of the buildings are over 45 years old and therefore predate the first law on energy saving, n. 373 of 1976. For Italy, the issue of housing conditions must be taken as the right of access to housing for the weakest social groups. To reach the 2030 target, the share of the population experiencing severe housing deprivation in urban areas must be reduced by two thirds, bringing it from the current $11.3 \%$ to below $4 \%$ (the current EU average is $4.8 \%$ ). Moreover, in this case, the aim must be achieved by intervening on the existing building and reconverting the degraded or abandoned areas, in close and inseparable connection with the interventions for urban regeneration, for the building's energy efficiency and the safety of the heritage [17].

Second, urban regeneration policies and in particular investments for new urban university campuses and services for students, which should be strongly integrated with the cities, represent a great unexpressed potential for the development of the communities in which they are included and would create useful actions in order to reach the theme of culture, education, and research, to which the case studies reported below refer. The theme is included in the Agenda 2030 for the Sustainable Development's goal 4 Ensure inclusive and equitable quality education and promote lifelong learning opportunities for all, in the target 9.5 Enhance scientific research, upgrade the technological capabilities of industrial sectors in all countries, in particular developing countries, including, by 2030, encouraging innovation and substantially increasing the number of research and development workers per 1 million people and public and private research and development spending and in the target 11.4 Strengthen efforts to protect and safeguard the world's cultural and natural heritage. Among its objectives, the European Union has the task of safeguarding the European common Cultural Heritage. Italy preserves the primacy in the list of artistic heritage, which constitutes a peculiar feature of the landscape with an expenditure of the Italian municipalities in 2014 for Cultural Heritage of $2.9 \%$ of the total, about 10 euros per capita, with strong differences between the north and south. In 2016, over 200,000 examples of real estate (architectural, archaeological, and museum) were subjected to the restriction, which is on average 67.6 per $100 \mathrm{sq} \mathrm{km}$; a very high density of historical and Italian value. Moreover, for investments in research and 
development, the national goal is to reach in 2030 the achievement of the percentage of $3 \%$ of GDP.

Regarding the theme of education, the objectives for urban areas are to reach, by 2025, the reduction of early school leaving to less than $10 \%$ in the 18-24 age group, and to achieve that $40 \%$ of adults in the $30-34$ age group be graduates. In $2015,14.7 \%$ of people had finished school early in cities $(14.8 \%)$, while in European cities they were less than the overall average $(9.8 \%)$. The $30-34$ years old's with university education were the last $25.3 \%$ in the EU (31.7\% in cities) [18].

\subsection{Pavia and the University: 660 Years of Joint History}

The University of Pavia is one of the oldest Italian and European Universities, formally established in 1361, when imperial vicar Galeazzo II Visconti asked Charles IV, the Bohemian king and Emperor of the Holy Roman Emperor, to found the Studium Generale, which had the same rights and dignity as the Universities in Bologna, Paris, Orleans, Montpellier, and Oxford [19].

The university is strongly characterized by the history and evolution of the town, growing during the centuries and creating a large building heritage, spread throughout the city, and distributed in three main campuses (Figure 1):

- The downtown campus, where the Human Science and Economics Departments and the most important Administrative Offices are located; these historical buildings have a high cultural value and they are listed as heritage buildings;

- The "Istituti Universitari" campus (University Institutes), where the Departments of Chemical and Physical Sciences and the "Medical" Institutes are set; this area is located in the north-west of the town, between the historic center and the main communication infrastructures (railway and bus station, and north-west ring road), and the healthcare centers (three hospitals "IRCCS"—Policlinico S. Matteo, Mondino Foundation, and Maugeri Foundation-in addition to the CNAO, National Centre for Hadrontherapy treatment);

- The Cravino Campus, where the Engineering, Mathematics, and Earth Sciences Centers are located, on the other site of the north-west ring road, bordering the Lombard countryside.

The University of Pavia also includes the Cremona campus, dedicated to the Faculty of Musicology, which will be not further considered in this work.

In Pavia there is also a strong tradition of colleges (10 public, managed by EDiSU, a special agency of the university, and seven private), hosting more than 2500 students coming from other Italian regions and other countries (Erasmus Programme and other International exchange programs).

It is easy to understand that it is a significant built heritage both in terms of size and quality, which daily hosts an academic community of over 26,000 people, divided into students $(23,500)$, professors and administrative staff $(2500)$, and random visitors attending different events (conferences, meetings, concerts, and graduation sessions, etc.).

This huge built heritage (52 buildings and approximately 250,000 sqm-without considering the colleges), founded over about eight centuries, has a series of different needs, such as energy efficiency optimization and issues related with accessibility and usability, considering that not all these buildings were realized to be academic seats.

In the last 10 years, the university developed some activities aimed at enhancing the buildings in the historic center, and in particular restoring buildings that were only partially used by the academic and social community. These interventions combine the renovation and redevelopment of real "pieces" of the city with the safety and adaptation in response to new regulatory requirements. Therefore, several structural and technological renovation interventions have been started (e.g., San Tommaso, Humanities Department and Library, and San Felice, which hosts the Department of Economics and Management), strongly aimed at sustainability and energy efficiency, through a larger use of renewable energy 
sources, and at safety and usability, through improving the spatial and functional quality of the university.

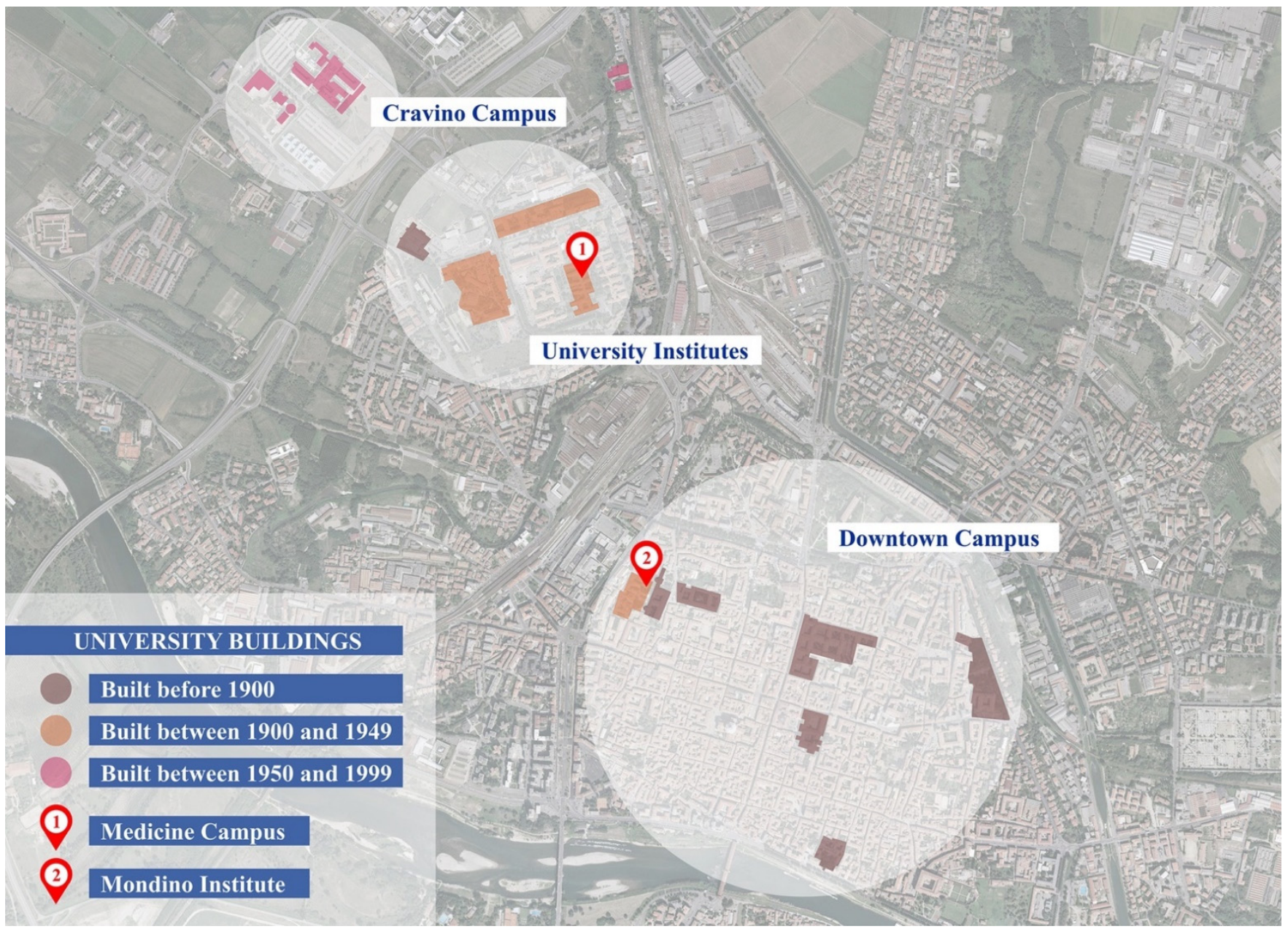

Figure 1. View of the city of Pavia with the three main campuses, divided into three main building periods. In red, the two case studies presented in this paper (Authors' image).

Moreover, the University of Pavia is working to increase the education provided and to develop new researching structures, setting up a series of building activities aimed primarily at adapting the existing heritage to the new teaching and research needs, including those issues that occurred due to the 2020 pandemic crisis.

Proceeding this idea, other projects are developed to reuse dismissed buildings in order to realize new didactic spaces, both for the scientific and the humanistic disciplines, and both in the downtown campus and in the "Istituti Universitari" area.

These projects are developed following an integrated approach, based on an in-depth knowledge of the authentic building characteristics (typology, materials, structural details, and technological installations, etc.) and a planning of interventions considering the available resources and the relationship with the urban environment and facilities [20].

The need for inserting and combining multiple functions in historical buildings (often not realized for academic functions, such as hospitals or monasteries) requires specific care in order to preserve and valorize the buildings and their historical, cultural, and social values [21]. The activities of the university and the hired professionals are based on a multidisciplinary and participated process, in order to control the full design and constructive phases, oriented to sustainable development of the university and of the town [22]. 


\section{Materials and Methods}

\subsection{Case Studies}

A total of two projects for reusing existing buildings-hospitals in the past, now designed to become education and study spaces for the students of the University of Pavia-are described in the following paragraphs.

Even if they are different projects (the new Faculty of Medicine and an Interdepartmental Library for the Department of Political Sciences and the Department of Law) and they are developed on existing buildings that have different and specific characteristics, they express the methodology aimed at returning to the city two buildings suitable for the new university needs according to an approach oriented towards the sustainable development from multiple points of view.

For each project, some topics are illustrated: the urban context in which it is inserted, a historical reconstruction of the building, a study of its morphological, typological, and structural characteristics, and the more general objectives of the University, to respond to its needs and design implications, which are focused on sustainability issues.

\subsubsection{The Faculty of Medicine}

The new location of the Faculty of Medicine is designed by reusing the former building of General Medicine within the Hospital complex of the IRCCS Policlinico San Matteo, located north-west of the historic center of Pavia (Figure 2).

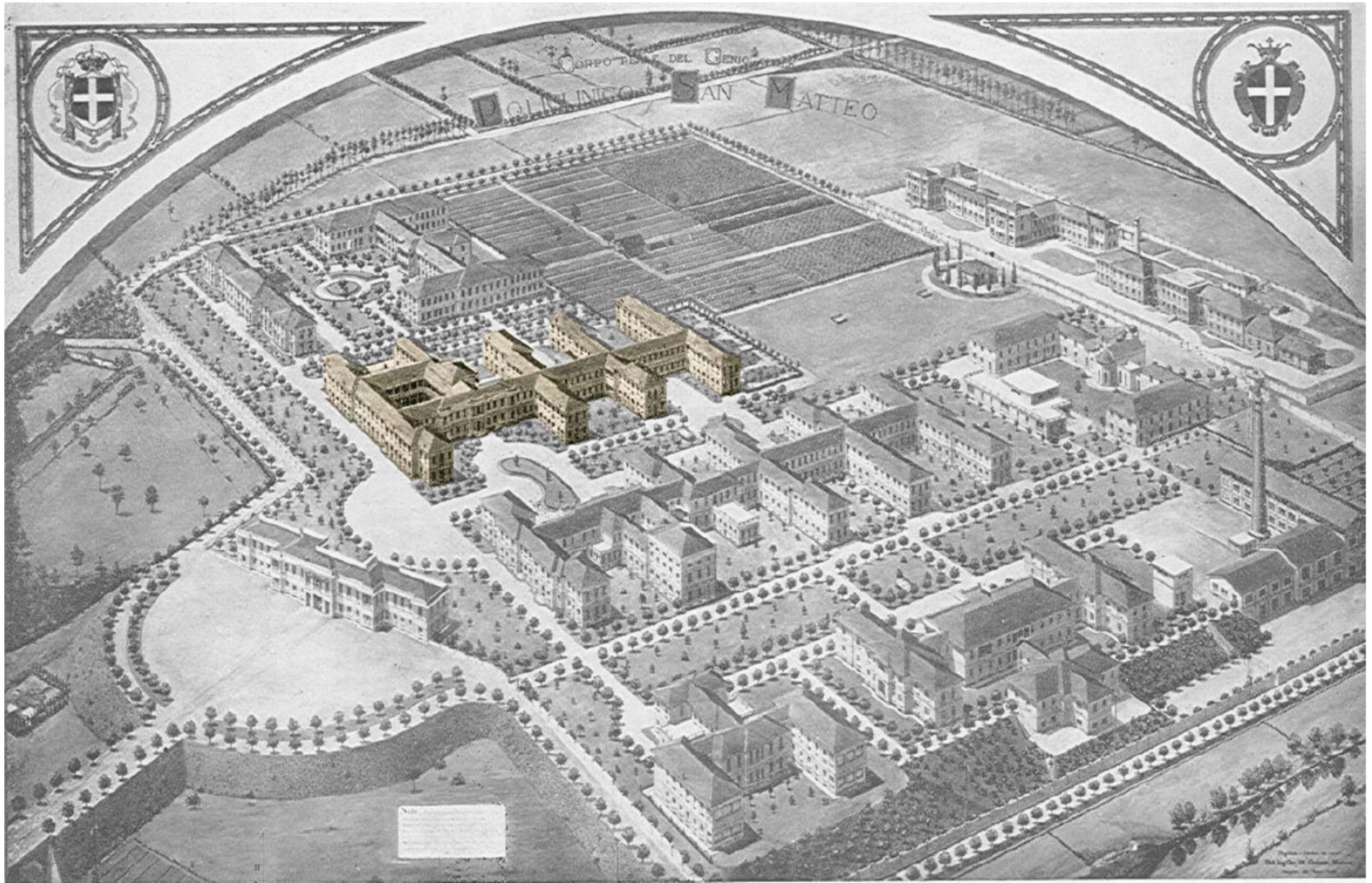

Figure 2. General view of the Hospital "S. Matteo" and some buildings of the university in the north side (1933). It is possible to recognize the building (now becoming the new Faculty of Medicine) by the closed courtyard (www.sanmatteo.org). The Hospital was built in an area not yet urbanized in the north-west side of the city center, where it could have grown further over the years, as occurred.

The intervention involves the creation of 16 classrooms (distributed over two levels) and 12 study rooms, the restoration of a historic hall (about 100 seats), a center for simulated teaching of healthcare disciplines, a medical library, and representative spaces (Dean's 
Office and workplaces for the administrative staff) as well as a cafeteria for a total of 9500 square meters.

The building, which was realized in the early 1930s and disused in 2013, has a length of approximately $160 \mathrm{~m}$ and $65 \mathrm{~m}$ in width, its surface is approximately 8700 square meters and is arranged on 2 levels: ground floor (approximately 4450 square meters) and first floor (approximately 4250 square meters). There is also an underground level, with shape and surface equal to the level above, connected with the rest of the building through internal staircases and two lifts. The height is almost constant along the entire perimeter and corresponds to about $9.30 \mathrm{~m}$, expect for the two volumes of the south side corresponding to the historic hall, which will be restored (Aula Ferrata, $12 \mathrm{~m}$ ), and to the single level volume built in the 1950s (4.5 m).

Considering the volumes, three elements can be distinguished: one at the head (south side), with a central plan, which encloses an uncovered courtyard; a longitudinal block that is about $115 \mathrm{~m}$ long (south-north direction), typologically such as a double build with a predominantly connective function; and seven transverse blocks ("teeth of the comb"), where the patients' beds were located.

The external areas are composed of a private asphalt road system of the hospital and flowerbeds that host numerous tree species, mostly concentrated in the central avenue that connects the north and south areas and facing the south facade of the new Faculty of Medicine.

The pavilion of the Medical Clinics exists within a pavilion complex consisting of various buildings (all built between the 1920s and 1930s) that have the same constructive and aesthetic-formal characteristics. The building is characterized as a typical hospital structure with pavilions, strongly desired by the Nobel Prize Camillo Golgi and inaugurated in 1932 [23].

The building system can be typologically defined as a "comb" with a long central axis that represents the corridor of distribution, from which the spaces that contained the sanitary functions in the past are alternated in order to have the maximum solar exposure possible, improving the sanitary and hygienic conditions of the patients (Figure 3).

Reviewing the documents and writings of the time, it is clear that some areas of the building are not part of the original construction; in particular, the expansion to the north was built in 1942, while the body located to the east of the internal courtyard was built in the 1950s, showing constructive characteristics different from the rest of the building [24].

These distinctions of the construction period are not particularly evident in the decorative apparatus of the facades, uniformed by moderate elements and characterized by plastered stringcourses of different colors, raised sills on the windows, and a frame below the eaves line of the roofs.

Fitting with the period of construction, the building consists of a loadbearing structure made up of bricks without thermal insulation and with a hollow block floor; the roof has pavilions, originally made of wooden trusses. The roof has undergone heavy alterations over the years, including the replacement of the main elements with reinforced concrete beams of poor consistency.

Between the different blocks, joined perpendicularly to the linearly connected and distributed building, there are green spaces, originally designed not only to make the views from the patients' rooms perceptually better but also for preserving the correct distance between the buildings, in order to ensure healthy air quality and guarantee optimal sunshine.

The buildings are part of the compositional system of the greenery that surrounds the original pavilions with tree-lined paths and flowerbeds that protect and mask the built volumes. For the creation of the green space, tall trees were chosen close to the walls to protect the entire hospital and hedges, flowering bushes, and smaller trees in the squared areas between the buildings, treated as small courtyards. At the beginning of the twentieth century, the Pavia Hospital, with its relationship between buildings and green spaces, already offered a very effective solution from a health point of view, which was well 
combined with an architecture that was not developed in height, demonstrating innovative solutions and ideas for those times [25].

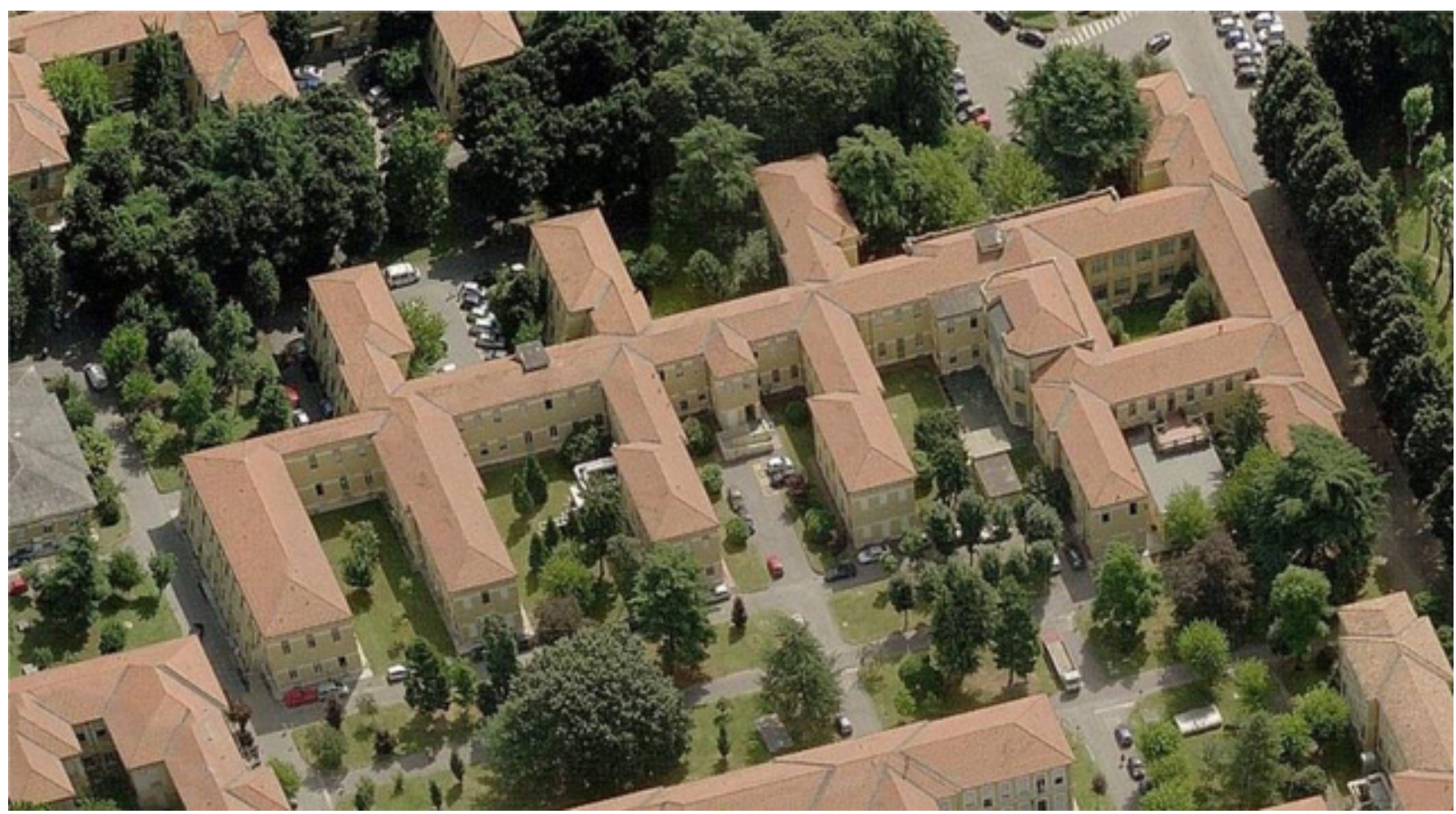

Figure 3. Aerial view of the Medical Clinics from the west. The green spaces between the different teeth of the "comb", essential for the well-being of the patients, can be appreciated by this point of view (https:/ /www.google.it/maps/).

After the movement of all the hospital functions inside the new building was inaugurated in 2013 (a building with a basement of three levels containing the Emergency Department and the surgical block and, in the towers above, nine floors of hospital rooms divided into different specializations), the Medicine Pavilion fell into disuse.

The design of the so called Healthcare Campus (unifying in one building the education and administrative activities of the 5 Medicine Departments that comprise the Faculty) began from these evidences; the project pursues some essential objectives both for the context in which it is inserted and for the university's strategies of development, among which the urban regeneration of a complex combination of high historical and cultural value and the concentration of the Faculty of Medicine in a single complex is undoubtedly solving the current fragmentation (Figure 4).

The number of classrooms, their capacity crowd, and the inserted equipment were decided by a team combined of professors, engineers, and architects in order to find the best solution able to balance the didactic needs with the structure of the building, which has to be conserved and valorized because of its historic value.

The reuse of the building (respecting all the Italian regulations about the conservation and valorization of the Cultural Heritage) with this new function allows to expand the education offer with a system of classrooms with differentiated capacities and multimedia configurations for the diverse didactic needs and in line with the most recent requirements for communication between spaces within the same building but also with the rest of the world (as required by the Distance Learning, which has extremely improved in the last two years). The creation of a simulated teaching center for the advanced medical area stands out both in terms of equipment for the simulation of interventions and in the multimedia kit for the best on-site and remote transmission of the experiences conducted. 


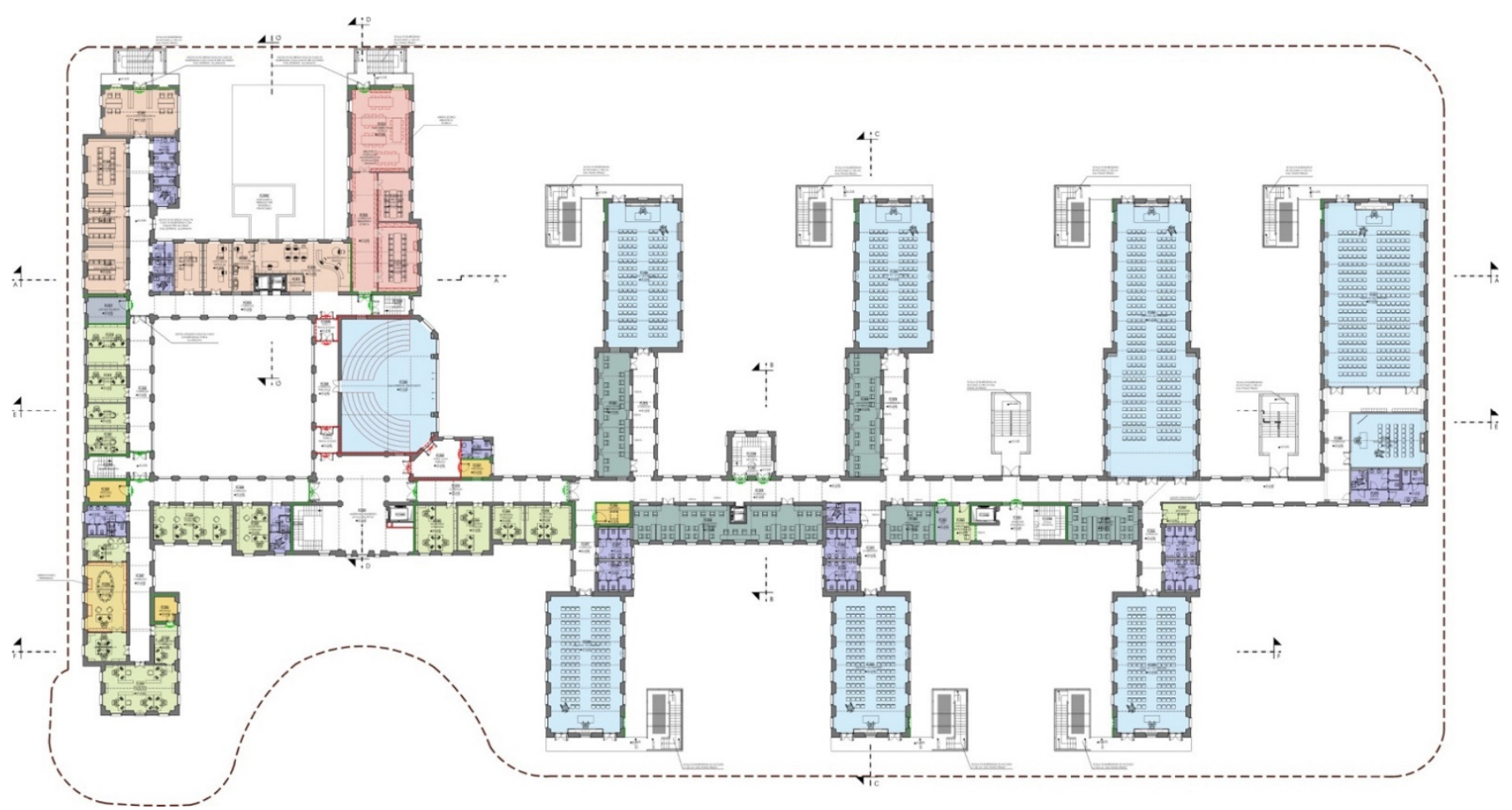

Figure 4. Functional layout of the first floor of the new Faculty of Medicine (light blue: classrooms; light green: offices; dark green: study rooms; light brown: library; red: historic library; violet: restrooms) (Image by the Technical and Safety Area of the University of Pavia).

At the same time and after proof of the residual performance on the building, the project allows for anti-seismic structural adaptation and energy improvement, with an intervention on the structure (with external, thermal insulation panels and windows substitution) and the insertion of new technical implants. Finally, the recovery and conservation actions on the historic hall (Ferrata Hall) and the ancient library-restoring and enhancing the original furnishings and concentrating on the library heritage of the medical area as a single place for consultation-make explicit the university's approach to the valorization of its properties.

All the actions and choices conducted in the management of the construction process seek to minimize time by ensuring the project quality. The construction site was open in September 2019, the work schedule assumes the conclusion of the construction in the second half of 2022, with the installation of furniture and equipment in the first half of 2023 and full use starting from the academic year 2023-2024.

The design choices for the new Faculty of Medicine, in continuity with a consolidated modus operandi of the University of Pavia, are adopted according to an approach oriented towards more general sustainability criteria, both environmental and social. The project contemplates the re-functionalization of the existing building, preserving its original typological structure according to the current Italian regulations for the conservative and restoration approach to the Cultural Heritage, with the consequent saving of soil and promotion of the protection and safeguarding of the existing building, in line with SDG 11 (Make cities and human settlements inclusive, safe, resilient and sustainable) and SDG 12 (Ensure sustainable consumption and production patterns) of the 2030 Agenda for Sustainable Development.

The project provides for overcoming architectural barriers (where their complete removal has not been possible) and an inclusive and multisensory signage, facilitating the use of the building and favoring the pursuit of SDG 4 (Ensure inclusive and equitable quality education and promote lifelong learning opportunities for all). Even if it was a hospital and it was designed considering weak users, the building was realized in a 
period far from the claim of the Universal Design or the Inclusive Design. Currently, the University of Pavia is engaged in the achievement of inclusion and attention to the needs of students with disabilities, which has led in recent years to expand the number of accessible buildings; the actions were developed owing to a participatory and coordinated work between engineers and architects of the Technical Area and doctors and psychologists of the Healthcare Area as well as professors from the various departments. The same approach is applied in this project, where a multidisciplinary team worked to find the best solution to make the building suitable for people with disabilities (Figure 5).

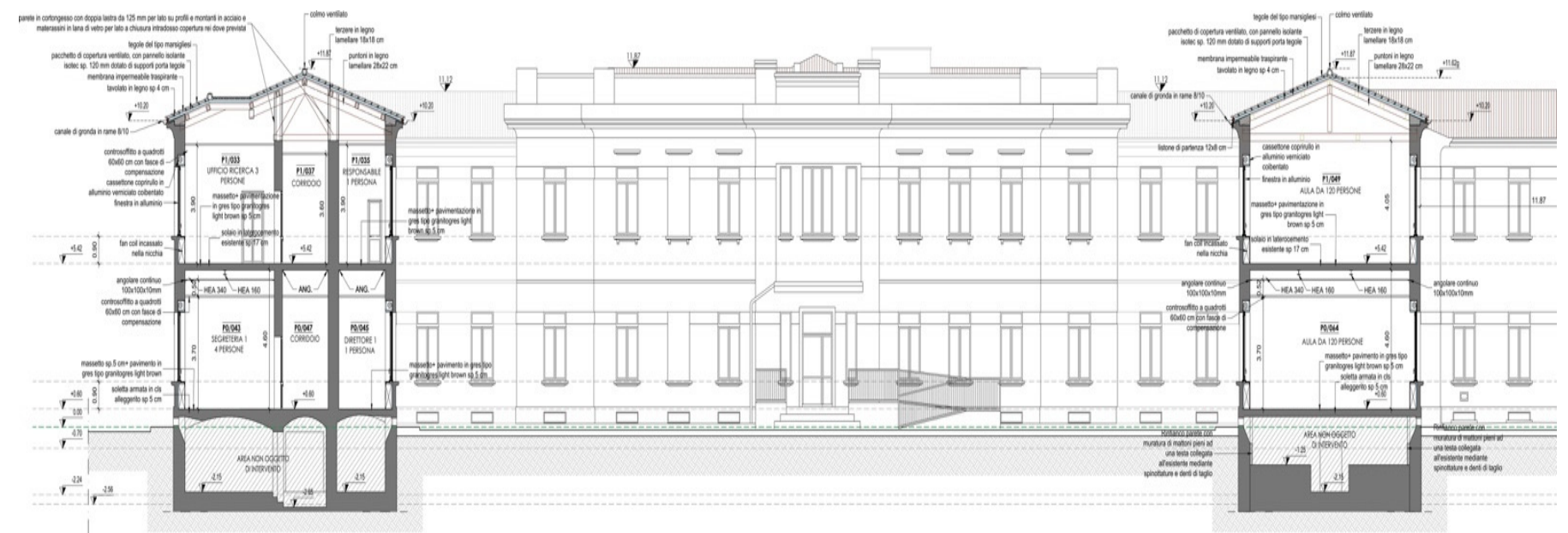

Figure 5. Section and façade of the new Faculty of Medicine in the former pavilion of General Medicine (Image by the Technical and Safety Area of the University of Pavia).

Regarding the adopted construction solutions, all the internal partitions are made with dry-layered plasterboard walls according to criteria of lightness, transformability, and reversibility, and the acoustic control (essential in a space that is densely frequented) is controlled by making extensive use of natural materials. Regarding the system solutions, the project provides for a photovoltaic system capable of producing more energy than that estimated necessary for the operation of the building, and a geothermal system for the air conditioning is installed.

Specifically, the photovoltaic system consists of the installation of multi-crystalline panels laid on the south roof. The photovoltaic field has a nominal power of about $108 \mathrm{kWp}$ and is built through the installation of 6 "fields" consisting of various panels, each of $250 \mathrm{Wp}$. The energy produced is fed directly into the power grid following the manner prescribed by the managing authority [26].

The construction of a new centralized air conditioning system is planned for the entire complex. The heat production is ensured by a hybrid system consisting of the derivation (through a slab heat exchanger) from the steam network directly managed by the hospital and from groundwater condensed heat pumps. The district heating substation is designed to guarantee the demand for heating. The production of chilled water for summer cooling is ensured by ground water condensed heat pumps. The dimension of the heat exchanger ensures the heat requirement for the entire complex and acts as a backup in the case of maintenance of the heat pumps. The groundwater supply is ensured by two dedicated wells, $70 \mathrm{~m}$ deep, equipped with submersible lifting pumps and related self-cleaning filters.

It is estimated that the design and energy choices, taken together, will stop the release of approximately 545 tons/year of $\mathrm{CO}_{2}$ into the atmosphere.

\subsubsection{The Interdepartmental Library of the Socio-Political Legal Area}

The project concerns the building complex known as the Neurological Institute of the Casimiro Mondino Foundation. It was the headquarter of the Institute from 1907 to 2003 and is currently under discussion. 
The location of the building is relevant both in the urban structure and in the context of the building assets of the university; it is located in the north-western quadrant of the historic center, near the decumanus of the Roman city (Corso Cavour) and is near to other university buildings (Palazzo Botta, Kosmos Museum, San Felice, and Palazzo Grassi). With these other historic buildings, it forms one of the largest university centers within the downtown campus [27]. This urban context is characterized by architectural emergencies, monuments, and relevant collective and institutional buildings. The current state of neglect, considering its strategic location, is an architectural, functional, and social "black hole".

The building was realised between 1904 and 1907, based on a project by the architect Savoldi. It has two floors above ground and an underground level, with two turrets that emerge at the north and south ends of the main façade, overlooking the public road, for a total of approximately 5670 square meters (Figure 6).

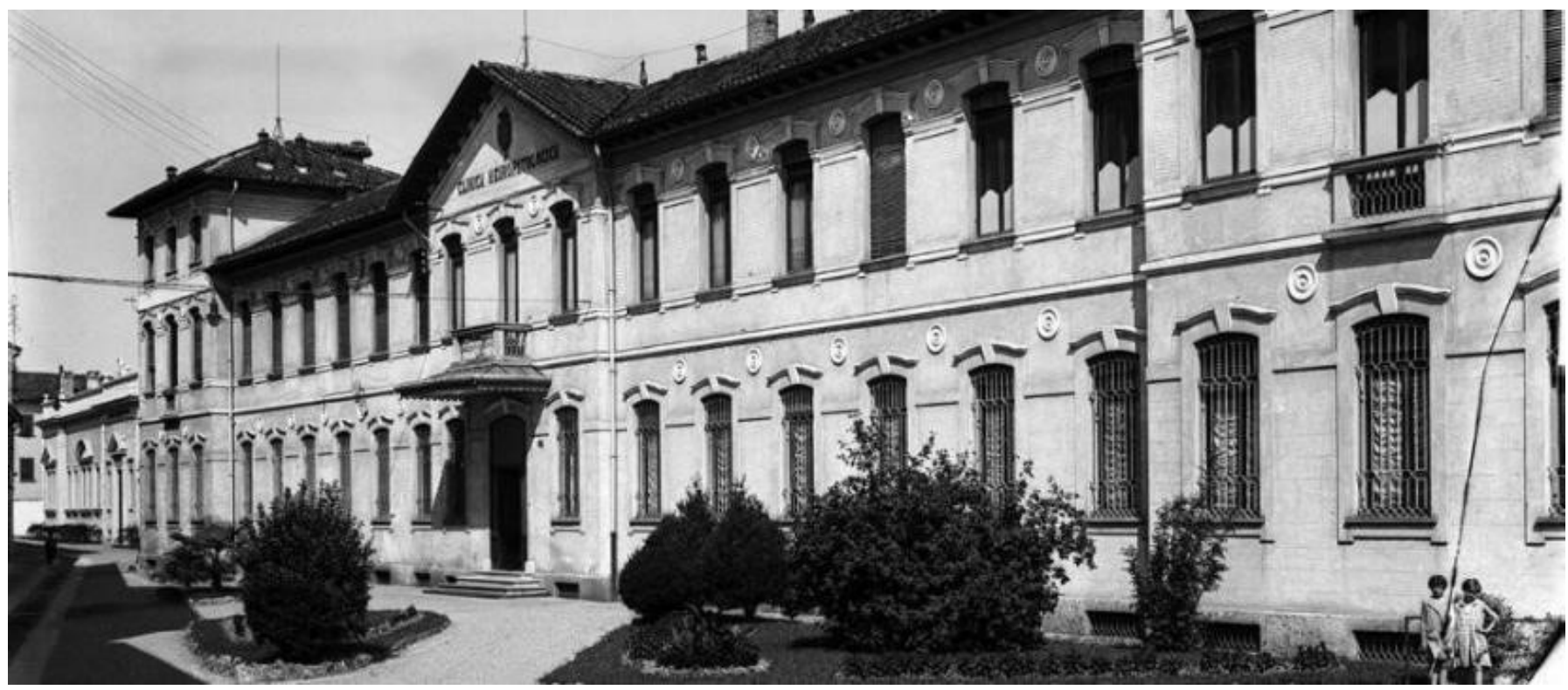

Figure 6. Main façade of the building in the early twentieth century. (Archivio Chiolini, Pavia, Musei Civici, CHLE_20_2_001).

Originally it was a neuropathological clinic, wanted by Professor Casimiro Mondino, professor of Psychiatry and apprentice of Lombroso and Golgi, illustrious scientists of the University of Pavia. The architecture follows the canons of the early twentieth century and the features of other similar buildings, including the asylum of Voghera $(30 \mathrm{~km}$ south from Pavia). At the same time, it presents solutions designed specifically for its destination, results of a participated design process by architect Savoldi and professor Mondino, as can be seen from the various distributive and organizational suggestions developed before reaching the definitive layout $[28,29]$.

The pavilion has a double soul, both clinical and didactic. The three blocks perpendicular to the main structure on the public street allow to meet educational and research needs and to keep male and female patients separate, taking advantage of the internal courtyards. In 1925, the clinic was expanded to the north with a new one-storey pavilion due to the will of Otorino Rossi, and it was subsequently transformed and adapted for functional needs [30]. With the transfer of the healthcare activities to the new headquarters in the north part of Pavia, not far from the other hospitals of the town, since 2003, the building has been gradually abandoned. Today it has evident signs of structural and material decay, as well as functional obsolescence.

The interdepartmental library project of the Mondino pursues a wide range of objectives, with virtuous effects on the city and on the university. In the first instance, the project involves the recovery and valorisation of a complex of great historical and architectural 
value, giving back to the city the reuse of a building with a great emotional impact and an important collective memory.

Precisely its location within the historical part of the city and its proximity to other institutional and educational centres allows to create mutual synergies and to trigger positive dynamics in the urban and social context, as a prototype of urban regeneration and environmental sustainability.

Moreover, from a functional point of view, the project for the unification of the departmental libraries of Law and Political and Social Sciences, currently fragmented in different spaces of the Central University Building, reorganizes the literatures' heritage both from an administrative and structural point of view (Figure 7). Furthermore, the actions to modernize and implement university structures and technologies are also aimed at making the university more attractive.

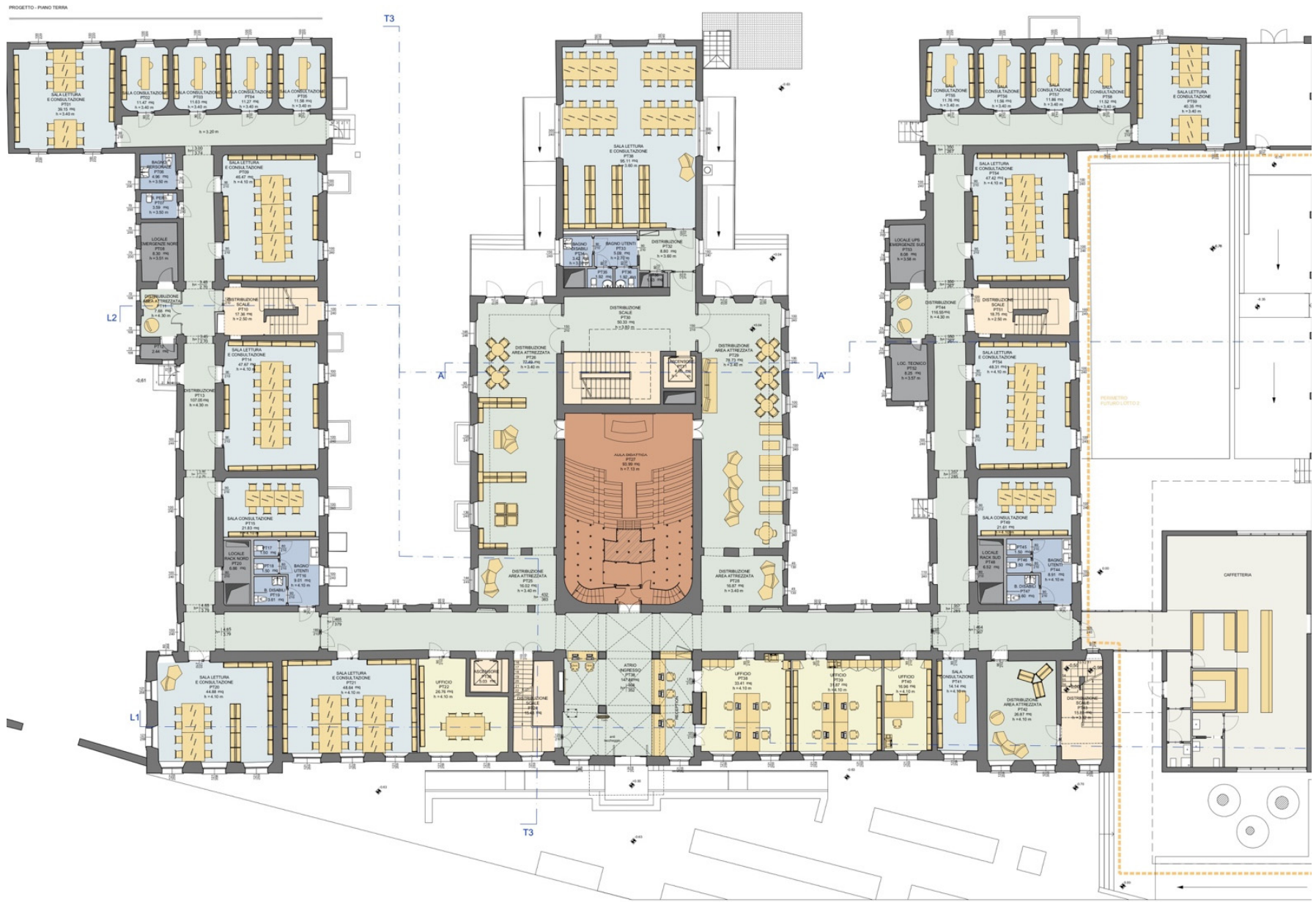

Figure 7. Layout of the ground floor of the interdepartmental Library set in Mondino. (light blue: reading rooms; light green: corridors and informal reading point; yellow: offices; blue: restrooms; grey: systems) (Image by TEA $\left.{ }^{+} \mathrm{M}\right)$.

In order to find the right balance between the needs of the Library Area of the University and the architectural organization and subdivision of the original building, a design group (architects, engineers, professors, researchers, and librarians) was arranged. They worked together for the period in which the project was developed and every step was verified by the Superintendence of National Heritage and Cultural Activities, so that the project was tested during its execution.

Finally, through the proposed project, the university moves in the direction of enhancing the quality of its services, with the creation of 350 seats in reading rooms, 10,000 m of shelves for books and magazines, and the restoration of a historic 80 -seat hall. This 
intervention respects the regulation for the public real estate assets under the structural, seismic, fire, acoustic, and plant engineering profile.

From these premises, it is clear that the project is strongly characterized by a sustainable philosophy, in continuity with the future development of the University of Pavia.

The choice of restoring, valorising, and reusing an abandoned historic building is an act with a strong environmental significance, which focuses on regeneration as a strategic value, an alternative to building from scratch, capable of combining the efficiency of modern technologies with evocative spatiality of historical architecture.

The design is based on the scientific restoration of the pavilions following the Superintendence recommendations, in order to preserve the memory of the building, enhance the original layout and the succeeding transformations, and make the building free from added elements without architectural value. The functions meet the natural vocation of the environments and the plants are integrated, respecting the architectural space. The result is an innovative project from a technical point of view, but one that is sustainable and compatible with the structure and type of building (Figure 8). The approach to the façade is conservative due to its architectural value (according with the Superintendence requirements) and differentiated between the principal façade on the main street and the secondary ones. Regarding the façade, a thermal plaster is applied, maintaining the original decoration and, in some part of the building, it has been possible to create insulated internal counter-walls. In relation to the ground floor and horizontal attic floor, it has been possible to operate with low thickness performing insulation that respects CAM criteria, in order to guarantee the transmittances required by law for new buildings.

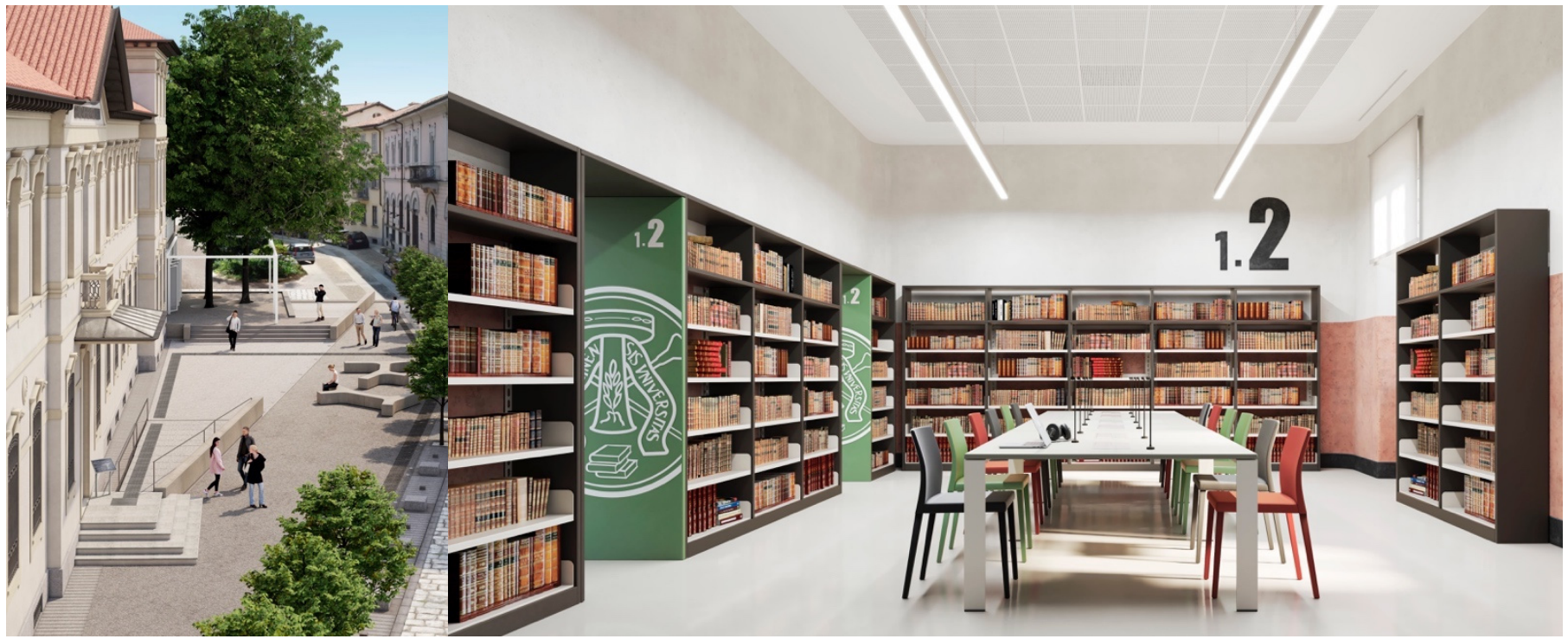

Figure 8. Rendering of the project: on the left, the entrance to the Library with the new pavements and urban furniture; on the right, an example of the reading room (Image by $\mathrm{TEA}^{+} \mathrm{M}$ ).

Considering windows and doors, the architectural constraint is different. On the main road (Palestro street), a conservative intervention with the restoration of the historical profiles and the replacement of the double glazing has been proposed. For the other façade, it has been possible to change to new ones with higher performances $(\mathrm{U}<1,3 \mathrm{~W} / \mathrm{mqK})$ and with a design of the profiles consistent with the original. Finally, the differentiation of the solar factor of the transparent parts has been proposed: $\mathrm{g}=0.35$ for the $\mathrm{SO}$ exposures to limit overheating from solar radiation in the summer and $0.40<\mathrm{g}<0.60$ for the exposures $\mathrm{NE}$, in order to take advantage of the free contributions in winter.

This project, as all the other University Libraries, will be open to the public, not only the academic community, so every kind of barrier (architectural and sensorial) is removed. 
IT and multimedia infrastructures are in line with recent upgrades in the sector; the lighting, essential in the design, is energy-efficient and managed by intelligent supervision with DALI technology, optimizing the available natural lighting. The summer and winter air conditioning systems exploit the on-site geothermal resource with high-efficiency heat pumps and technological solutions for reducing consumption (inverter pumps, air recuperators, and $\mathrm{CO}_{2}$ sensors).

The internal systems are equipped with low temperature radiant panels and primary air for a precise control of both summer and winter humidity with a view to thermohygrometric comfort, the preservation of books and paper bindings, and also to obtain the environmental safety of users in the current COVID-19 era, owing to the total absence of recirculation [31].

\section{Results}

The two case studies presented in this paper are quite different, even if they were both hospitals originally and are now educational buildings. They were built at the beginning of the XX Century with the same technologies and distributive organization as healthcare buildings, but now the first one is a didactic building while the second one is a library (spaces for studying and researching).

The Faculty of Medicine is strictly connected with the clinical activities of the San Matteo Hospital, where many professors work as doctors. This contiguity represents an added value compared to another location (which the university had also considered when deciding to have a new location for the Faculty). Even if the function of the building has been changed (from hospital to university) the relationship with the surroundings has been enhanced. The building was born as the heart of the hospital during the 1930s, and now it hosts all the didactic and administrative needs of the faculty, spread in obsolete buildings not only in this area.

The interdepartmental library is set outside the two departments involved (650 m far from the Main Building of the University), but it is connected with other university buildings and its location can transform the urban environment, creating a new relationship with the other nearby public functions (there are two public institutes - a primary and a secondary school - on the south side and a hospital on the north side). The new function proposed for the building is the expression of academic needs, but it has also been supported by the urban surroundings, such as a museum, other departments of the university, and some schools, thus creating a cultural network in the city center not far from the main infrastructure connection.

However, the approach and the method applied by the university to develop the project are the same:

- The projects are the results of a process with the involvement of different professionals, each with specific skills coordinated and managed by the Technical and Safety Area of the University;

- The respect of the original buildings, their open spaces, and their context, in order to maintain the memory and the social value of part of Pavia;

- The use of innovative technologies, considering the constraints coming from the intervention on protected buildings; every solution is addressed to improve the quality and safety of the spaces, ensuring to the users the right comfort, and to the university the management and maintenance of costs, making use of solutions that respect the environment;

- The effort to find inclusive solutions, whilst respecting the needs of people with disabilities, and with the awareness that the access to places of education and culture is an indispensable prerequisite for equitable and sustainable development.

In addition, both the two projects follow the guidelines of the 17 Goals of the 2030 Agenda for the Sustainable Development [32], with a specific attention to SDG 4 (Ensure inclusive and equitable quality education and promote lifelong learning opportunities for 
all), SDG 11 (Make cities and human settlements inclusive, safe, resilient and sustainable) and SDG 12 (Ensure sustainable consumption and production patterns).

\section{Discussion}

The two case studies presented demonstrate how the strategies of the University of Pavia are planned through a multidisciplinary and participatory systemic and sustainable approach.

The multidisciplinary approach is an essential condition for dealing with complex buildings dedicated to research and education; the spaces for simulated teaching could not have been adequately organized and distributed without the collaboration of the professors of the Faculty of Medicine who will use the spaces (and for which dimensions and subdivisions have been verified several times on site). At the same time, an interdepartmental library could not have been structured and divided into the places obtained from the elimination of the unoriginal elements in the former Mondino without the contribution of the Cultural Heritage Area and the involved professors and researchers of the departments dealing with the heritage of the books.

Furthermore, during the in-progress design activities, the university implemented a participatory process that was not limited to the contribution of the professors and researchers of the areas involved, but also included the stakeholders for the authorizations issue (Superintendence, Municipal Administration, and Fire Brigade, etc.). During the planning, design meetings were organized regularly (mainly online in the pandemic period, and on site as soon as the emergency conditions allowed it) with the various officials and managers, who were not only able to follow the development of the project idea but also, if necessary, indicate in advance some solutions to accelerate the subsequent authorization process, being aware of the motivations and design choices made.

The systemic vision is as fundamental as it is complex: each project design (especially if it concerns buildings that are significant from a dimensional point of view) must be read within an articulated system, divided into three campuses, which comprise 52 buildings for 225,000 square meters, all within which there are 18 departments and an academic community comprising over 27,000 people. It would therefore be limiting to consider each project individually, because the consequences of each intervention are transversal to many areas and involve several components. Therefore, the Technical and Safety Area of the University plans and organizes interventions in synergy with the other areas in which the university is structured (research, didactic, crowdfunding, cultural heritage, and sport), coordinating and directing activities with the aim of achieving the highest degree of satisfaction of the entire academic community and not only of the users directly affected by the single project.

No less important is the sustainability topic, not to be understood exclusively as environmental one, but also social and economic. The interventions mentioned above, and those that the university shall develop in the next few years, will lead to an increase in spaces available for the academic community but they will also need to be heated and cooled, cleaned, and connected to the network and power supplies for the various devices necessary for teaching and research activities, which will lead to an increase in management costs. For this reason, every possibility of limiting energy consumption, exploiting renewable resources, and rationalizing and optimizing the use of spaces and equipment is essential to allow the university economic and also social sustainability, and to be understood as sharing intentions, methods, and goals for the community.

Owing to this kind of approach, at the beginning of the design process there was a deep analysis about the different degrees of severity occurring from the distributive and technological characteristics of the buildings. The large distributive corridors and the big rooms (occupied by beds in the past) which had been placed to receive the best sunlight were interpreted as opportunities to create distribution spaces, which would become informal meeting places for the academic community and high-capacity classrooms, without distorting the original typological characteristics. 


\section{Conclusions}

The actions of reuse, re-functionalization, and enhancement of the existing heritage not only move according to the dictates promoted by the SDG's of the 2030 Agenda but trigger social regeneration policies in the relations between the university and the city.

The location of the buildings allows to create a new relationship with the urban environment; the Healthcare Campus is inserted in the Area of the IRCCS Policlinico San Matteo so that the students attending the Medicine Courses can move between the new didactic building and the wards where the internships are arranged. The new library is open to the town (as all the other academic libraries) and it is close to different primary and secondary schools, so that a new learning and cultural center is going to grow in the western part of the downtown.

The shape (typology) of the buildings and their distributive characters (corridors and big dormitories placed to receive the best sunlight and warmth during the day; green courtyards between the blocks that create a "comb" and wide structural span) make it easy to transform them in to learning places, with large corridors to reach the different rooms where the students can meet and find an informal place of study and big halls where lectures and conferences can be held.

They create consolidated places of common living and engines of economic development and management. They supply nodes of the vast range of interrelated functionsknowledge, experimentation, and innovation centers-and focal points of creativity and culture, as well as places of inclusion and social integration [33].

The approach and methods applied both in the Healthcare Campus and in the Unified Library of the Social Political and Legal Area represent a strategy that can not only be extended to other buildings of the university, but which can be applied by other operators who are involved with complex and articulated real estate assets that want to pursue sustainable development.

Author Contributions: Conceptualization, A.G., D.B. and V.G.; methodology, A.G., D.B. and V.G.; resources, M.M., S.L., A.B., R.T. and C.R.; data curation, M.M., S.L., A.B., R.T. and C.R.; writingoriginal draft preparation, A.G., D.B. and V.G.; writing-review and editing, A.G. and D.B. All authors have read and agreed to the published version of the manuscript.

Funding: This research received no external funding.

Institutional Review Board Statement: Not applicable.

Informed Consent Statement: Not applicable.

Data Availability Statement: The data presented in this study are available on request from the corresponding author.

Conflicts of Interest: The authors declare no conflict of interest.

\section{References}

1. Losasso, M. Urban regeneration: Innovative perspectives. TECHNE 2015, 10, 4-5.

2. Burdett, R. Infrastructure, public spaces and housing retrofitting in the experience of urban regeneration in London. TECHNE 2015, 10, 19-23.

3. Lewis, O.; Sadhbh, N.; Borghi, A. Building Energy Efficiency in European Cities. 2013. Available online: https://urbact.eu/sites/ default/files/import/general_library/19765_Urbact_WS6_ENERGY_low_FINAL.pdf (accessed on 24 January 2022).

4. Paris, S.; Bianchi, R. Architectural and environmental retrofit of public social housing: Opportunity for contemporary city. A case history in Rome. TECHNE 2015, 10, 204-213.

5. Di Giulio, R. Paesaggi Periferici. Strategie di Rigenerazione Urbana; Quodlibet Studio, Città e Paesaggio: Macerata, Italy, 2013.

6. Perulli, P. Visioni di Città. Le Forme del Mondo Spaziale; Einaudi: Torino, Italy, 2009.

7. Ave, G. Sostenibilità Ambientale e Rigenerazione Urbana; Alinea: Firenze, Italy, 2003.

8. Focà, A.; Laganà, A. Nuove responsabilità: Ripensare alla rigenerazione. TECHNE 2015, 10, 179-185.

9. Musco, F. Rigenerazione Urbana e Sostenibilità; Franco Angeli: Milano, Italy, 2016.

10. Ciorra, P.; Marini, S. Re-Cycle. Strategie per L'architettura, la Città e il Pianeta; Electa: Milano, Italy, 2011.

11. Marini, S.; Corbellini, G. Recycled Theory: Illustrated Dictrionary; Quodlibet Studio, Città e Paesaggio: Macerata, Italy, 2016.

12. Besana, D. Progettare il Costruito tra Conoscenza e Interpretazione; Alinea Editrice: Firenze, Italy, 2008. 
13. Bonetti, T.; Marzot, N.; Roversi Monaco, M. Frammenti per un Codice del Ricilo Urbano; Aracne: Roma, Italy, 2016.

14. Di Lascio, F.; Giglioni, F. La Rigenerazione di Beni e Spazi Urbani. Contributi al Diritto delle Città; Il Mulino: Bologna, Italy, 2017.

15. Angelucci, F.; Di Sivo, M. Resilience and Quality of the Built Environment between Vulnerabilities and New Values. The Role of Technological Planning. In Society, Integration, Education; Rezekne Higher Educ Inst-Rezeknes Augstskola: Rēzekne, Latvia, 2013; Volume IV, pp. 91-102.

16. Fanzini, D.; Rotaru, I. Inclusive Processes and project anticipation for urban and territorial regeneration. TECHNE 2015, 10, 102-109.

17. The 17 Goals. Available online: www.sdg.un.org (accessed on 11 January 2021).

18. Alleanza Italiana per lo Sviluppo Sostenibile. Available online: www.asvis.it (accessed on 11 January 2021).

19. Erba, L. Alma Ticinensis Universitas; Università Degli Studi di Pavia: Pavia, Italy, 1990.

20. Greco, A.; Giacometti, V.; Rota, M.; Senaldi, I.E.; Penna, A. Integrated Strategies for preserving and enhancing the Historical Heritage of the University of Pavia. Sustainability 2021, 13, 783. [CrossRef]

21. Morandotti, M. La valorizzazione sostenibile dei beni culturali, vincoli di riuso e soglie di fruizione. In Studiare e Progettare L'accessibilità Degli Edifici Storici, 1st ed.; Greco, A., Ed.; EdicomEdizioni: Monfalcone, Italy, 2013; Volume 1, pp. 69-84.

22. Morandotti, M. Resilicor an approach to the sustainable transformability of immovable Cultural Heritage. In [RICH*], 1 st ed.; Besana, D., Ed.; Aracne: Roma, Italy, 2017; Volume 1, pp. 55-76.

23. Gnocchi, L. L'Ospedale San Matteo e le Cliniche Universitarie; Ospedale San Matteo: Pavia, Italy, 1933.

24. Mantovani, D. Almum Studium Papiense. Storia dell'Università di Pavia; Cisalpino: Milano, Italy, 2021; Volume 3.

25. Zanetti, D. L'Ospedale San Matteo di Pavia. Fatti e Problemi del Passato; Amministrazione dell'Ospedale San Matteo di Pavia: Pavia, Italy, 1995.

26. Relazione Tecnica Costruttiva dei Progettisti Relativa al Recupero e Rifunzionalizzazione del Padiglione Cliniche Mediche del Complesso Ospedaliero del Policlinico San Matteo per la Creazione del Nuovo "Campus della Salute"; University of Pavia: Pavia, Italy, 2018.

27. Zatti, S. Note urbanistiche sulla fondazione della Clinica Neuropsichiatrica di Pavia. In Conferenze e Seminari, 1st ed.; Ceroni, M., Martigoni, E., Molinari, S., Eds.; EDS: Pavia, Italy, 1997.

28. Greco, A.; Besana, D.; Giacometti, V.; Frigerio, L. La clinica Neuropatologica Mondino di Pavia: Un impianto tipologico simmetrico e versatile. In La Città e la Cura., Spazi Istituzioni, Strategia, Memoria; AISU International: Torino, Italy, 2021.

29. Musei Civici di Pavia, Fondo Savoldi, Cartella C 1-3. Available online: https://museicivici.comune.pv.it/site/home.html (accessed on 24 January 2022).

30. Vaccari, P. Storia dell'Università di Pavia; Università di Pavia: Pavia, Italy, 1957.

31. Turino, R.; Ruggeri, C. Relazione Tecnica Costruttiva dei Progettisti Relativa al Recupero e Rifunzionalizzazione dell'ex Clinica Neuropatologica Mondino per la Creazione della Biblioteca Unificata dell'area Socio Politico Giuridica dell'Università di Pavia; TEA ${ }^{+} \mathrm{M}$ Pavia, Italy, 2020.

32. United Nations. The 2030 Agenda for Sustainable Development; UN: New York, NY, USA, 2015.

33. Her, O. The Road to Success, Integrated Management of Historic Towns Guidebook; Stadt Regensburg: Regensburg, Germany, 2011. 